\title{
EFFECT OF BETAMETHASONE ON THE PULP AFTER TOPICAL APPLICATION TO THE DENTIN OF RAT TEETH: VASCULAR ASPECTS OF THE INFLAMMATION
}

\author{
Elaine Vianna Freitas FACHIN ${ }^{1}$, Roberta Kochenborger SCARPARO ${ }^{2}$, Ana Paula Weissheimer PEZZI ${ }^{3}$, \\ Simone Bonato LUISI ${ }^{4}$, Manoel SANT'ANA FILHO ${ }^{5}$
}

\author{
1- DDS, MSc, PhD, Associate Professor, Department of Conservative Dentistry, Dental School, Federal University of Rio Grande do Sul, Porto Alegre, \\ RS, Brazil. \\ 2- DDS, MSc, Substitute Professor, Department of Conservative Dentistry, Dental School, Federal University of Rio Grande do Sul, Porto Alegre, RS, \\ Brazil. \\ 3- DDS, MSc, Graduate Student, Department of Conservative Dentistry, Dental School, Federal University of Rio Grande do Sul, Porto Alegre, RS, \\ Brazil. \\ 4- DDS, MSc, PhD, Assistant Professor, Department of Conservative Dentistry, Dental School, Pontifical Catholic University of Rio Grande do Sul, \\ Porto Alegre, RS, Brazil. \\ 5- DDS, MSc, PhD, Associate Professor, Department of Conservative Dentistry, Dental School, Federal University of Rio Grande do Sul, Porto Alegre, \\ RS, Brazil.
}

Corresponding address: Dra. Elaine Vianna Freitas FACHIN - Universidade Federal do Rio Grande do Sul - Faculdade de Odontologia - Departamento de Odontologia Conservadora - Rua Ramiro Barcelos, 2492 - 90035-003 Porto Alegre, RS - Brasil - Phone: +55-51-3308 5430 / 33085005 - e-mail: efachin@hotmail.com

Received: April 23, 2008 - Modification: September 21, 2008 - Accepted: November 09, 2008

\begin{abstract}
$O$

bjective: This study investigated the pulpal effect of topically applied betamethasone to the dentin of rat molars in the vascular phase of inflammation. Material and Methods: Deep cavities were prepared on the occlusal face of the maxillary right and left 1st molars with non-refrigerated inverted-cone steel burs at low speed. Three groups were formed: Group I was composed of right 1st molars; Group II was composed of left 1st molars that received the application of a drop of betamethasone on dentin surface for 5 min; and Group III (control) was composed of right 2nd molars that received no cavity preparation or betamethasone application. Changes in the vascular characteristics of the pulp tissue were checked by calculating the pulp vascular area in relation to its total area and the number of blood vessels per unit area. Data were subjected to ANOVA and Tukey's test $(\alpha=0.05)$. Results: Group I presented a significantly larger number of vessels $(\mathrm{p}<0.05)$ than Group II. Regarding the vascular/total area ratio $(\%)$, Group I presented statistically significantly higher values $(\mathrm{p}=0.01)$ than Groups II and III. Conclusion: Betamethasone applied on the dentin of rat teeth proved to reduce the vascular phase of pulp inflammation regarding vessel diameter and number of blood vessels.
\end{abstract}

Key words: Inflammation. Dental pulp. Betamethasone.

\section{INTRODUCTION}

Inflammation is a local reaction of vascular tissues characterized by loss of liquid and blood cells to the extravascular environment or interstice. This reaction may be induced by biological, physical or chemical agents ${ }^{1,4,19}$.

The vascular phase corresponds to the very first events of the inflammatory process. After aggression to the tissue, the arterioles undergo a constriction mediated by autonomous nervous fibers, lasting no longer than $5 \mathrm{~s}$. Immediately after this constriction, endogenous chemical mediators promote vasodilatation, arteriolar at first, with resulting increase in the vascular hydrostatic pressure (hyperemia). As more and more blood goes through the vessels, both capillary vessels and venules become dilated. The action of chemical mediators and the increased intravascular pressure also promote an increase in vascular permeability, leading to exudation and edema $^{4,19}$.

In the pulp tissue, the first stage of potentially reversible inflammation is known as pulpal hyperemia, clinically characterized by provoked, temporary, localized, low-intensity pain. Given that this tissue is closely related to the dentin, forming the dentin-pulp complex, the pulp can be affected by aggressions to the dentin ${ }^{2,12,20}$. Moreover, due to the intimate relation between these tissues and the dentinal permeability, molecules of medications, such as corticosteroids, applied on the exposed dentin, diffuse through the dentinal tubules, with the potential to provide a therapeutic effect, alleviating the painful symptom ${ }^{6,15}$.

The therapeutic effect of corticosteroids is based on their action on the synthesis of lipocortin and vasocortin, inhibiting the formation of edema and $\mathrm{A}_{2}$ phospholipasis enzymes, 
respectively. By inhibiting this enzyme, membrane phospholipids cannot be converted into aracdonic acid. Therefore, the synthesis of prostaglandins and prostacyclins (the cyclooxygenase route) as well as the synthesis of leukotrienes (the lypooxygenase route) that should follow, are blocked ${ }^{9,19}$. According to Rittner, et al. ${ }^{16}$ (2003), the production of bradicinin and prostaglandins could regulate the onset of pain. Nakanishi, et al. ${ }^{14}$ (2001) point out that pulpal fibroblasts and macrophages can participate in the production of prostaglandins by means of cyclooxygenase- 2 expression in the pulpal inflammation, and both can be involved in the pathogenesis of pulpitis. That is why the application of an antiinflammatory agent inhibits edema, vasodilatation and the chemotactic effects on leukocytes. Moreover, corticosteroids will act on histamine, heparin, and bradicinin, which are important chemical mediators in the initial phases of acute inflammation ${ }^{6,16}$. The activation of the cinin system results in the release of bradicinin norpeptide. This vasoactive agent can induce arteriolar dilatation, increase venule permeability and cause pain ${ }^{3,16,19}$.

Since the 1960s, corticosteroids have been used on dentin in order to diminish dentinal hypersensitivity and pulpal hyperemia. Hyperemia is a condition derived from a set of physical, chemical and bacterial aggressions produced by cavity preparation, restorative materials and caries disease. Several authors ${ }^{6,11,12}$ have discussed whether hyperemia can be treated by using topical corticosteroids on dentin and have suggested that it is possible to prevent this hypersensitive reaction with topical application of the medication on the dentin prior to restoration. Ciarlone and Pashley ${ }^{3}$ (1992) are in accordance with this viewpoint when they affirm that drugs can be used as a conservative mode of treatment during the initial phases of pulpal inflammation, capitalizing on dentinal permeability. However, it should be pointed out that, although this practice has been recommended by the authors above mentioned, most studies in that investigated the action of topical corticosteroids in endodontic applications evaluated the direct use of these drugs on the pulp to minimize inflammation or pain ${ }^{13,17}$.

Considering the clinical relevance of prevention in the development of irreversible pulp inflammation and the scarcity of more recent studies attesting the hypothesis that corticosteroid antiinflammatory medication is effective under these circumstances, the present study investigated the pulpal effect of topically applied betamethasone to the dentin of rat molars in the vascular phase of inflammation.

\section{MATERIAL AND METHODS}

The research protocol followed in this study was reviewed and approved by the Research Ethics Committee of the Dental School of the Federal University of Rio Grande do Sul, Porto Alegre, RS, Brazil.

Six male rats (Rattus norgeviccus albinus Wistar), age 90-120 days and weight 300-400 g, were used for testing the immediate effects of betamethasone on the pulp tissue when applied on the dentin exposed from a deep cavity preparation. One animal was lost during the experimental phase, reducing the size of the groups to 5 animals.

The animals were pre-anesthetized with $2 \%$ xylazine hydrochloride (Virbac do Brasil, Juruatuba, SP, Brazil; $1 \mathrm{mg}$ / $\mathrm{kg}$ body weight) and were then anesthetized with a combination of tiletamine hydrochloride and zolazepam hydrochloride (Virbac do Brasil; $20 \mathrm{mg} / \mathrm{kg}$ body weight). Deep cavities were prepared on the occlusal surface of the maxillary right and left 1st molars with non-refrigerated 331/2 inverted-cone steel burs at low speed (KG Sorensen, São Paulo, SP, Brazil). The depth of the cavities was standardized in approximately $0.6 \mathrm{~mm}$, which corresponds to the active part of the bur. Preparation aimed at inducing a pulpal inflammatory response (hyperemia) without exposing the pulp $^{20}$. After cavity preparation, three study groups were defined: Group I was composed of right 1st molars; Group II

TABLE 1- Mean number of blood vessels per $100 \mu \mathrm{m}^{2}$ recorded in the groups

\begin{tabular}{lll}
\hline Group & $\mathbf{n}$ & Mean (standard deviation) \\
\hline I (no medication) & 5 & $4.33^{\mathrm{A}}(1.74)$ \\
II (betamethasone) & 5 & $2.40^{\mathrm{B}}(0.55)$ \\
III (control) & 5 & $2.80^{\mathrm{AB}}(0.81)$ \\
\hline
\end{tabular}

Means followed by same letter do not differ significantly.

TABLE 2- Percentage of vascular pulp area in relation to the total pulp area recorded in the groups

\begin{tabular}{llcc}
\hline Group & $\mathbf{n}$ & Mean (standard deviation) & $\mathbf{p}$ \\
\hline I (no medication) & 15 & $48.41^{\mathrm{A}}(16.27)$ & $\leq 0.01$ \\
II (betamethasone) & 15 & $20.85^{\mathrm{B}}(7.11)$ & $13.18^{\mathrm{B}}(3.01)$ \\
III (control) & 15 & $13.01)$ & \\
\hline
\end{tabular}

Means followed by same letter do not differ significantly. 
was composed of left 1 st molars that received a drop of betamethasone (Pharmacus, Porto Alegre, RS, Brazil) on dentin surface for $5 \mathrm{~min}$; and Group III (control) was composed of right 2 nd molars that received no cavity preparation or betamethasone application. Thus, Group I represented pulp response after non-medicated cavity preparation, Group II, pulp response after application of a corticosteroid antiinflammatory medication, and Group III represented the condition of pulpal vascular normality.

The animals were sacrificed by hypoxia caused by cervical dislocation 10 min after cavity preparation and the samples from the right and left sides were removed and fixed in $10 \%$ neutral formalin for $24 \mathrm{~h}$. The pieces were decalcified with Ana Morse solution (equal parts of sodium citrate and formic acid), which was renewed every $48 \mathrm{~h}$ and daily agitated to speed up decalcification. After decalcification, the pieces were embedded in paraffin and 4- $\mu$ m-thick sections were cut in a buccolingual direction, starting from the first cut where the pulp could be visualized, and were stained with hematoxylin and eosin.

Three representative histological sections showing the pulp core were selected from each tooth. Three teeth (one for each group) were evaluated from each animal, providing 15 histological sections per group and 45 in the total sample. The microscopic slides were evaluated in a blind procedure by one calibrated examiner.

Changes in the vascular characteristics of the pulp tissue were checked by calculating the pulp vascular area in relation to its total area and the number of blood vessels per unit area. In this way, the magnitude of vasodilatation, which is a typical event of the initial phases of the inflammatory process, could be investigated. Image Tool 3.0 software (UTHSCSA, San Antonio, Texas, USA) was used to demarcate the total area of the pulp for each histological section and for each vessel visualized. For such purpose, the software's area measurement tool was used and the contour of the area to be measured was defined using the computer's mouse.

In each histological section, the areas of all vessels were summed and this was used to calculate the vascular/total pulp area ratio, which was expressed percentage. The number of vessels in each section was counted for each cut and this number was used to calculate the number of vessels per unit area $\left(100 \mu \mathrm{m}^{2}\right)$. The values for number of vessels and vascular/ total area ratio obtained in the 3 histological sections prepared for each of the 5 teeth in each group were averaged to provide mean values that were used for intergroup comparisons.

Data were subjected to statistical analysis by ANOVA and Tukey's multiple-comparison test using the SPSS 10.0 statistical software (SPSS Inc., Chicago, IL, USA). Significance level was set at $5 \%$.

\section{RESULTS}

Table 1 presents the differences between the groups regarding the number of vessels per $100 \mu^{2}$. Group I (cavity preparation with no subsequent application of corticosteroid) presented a significantly larger number of blood vessels $(\mathrm{p}<0.05)$ than Group II (teeth were medicated with application of a corticosteroid antiinflammatory on dentin surface). The blood vessels in Group I were clustered and presented erythrocytes filling up the whole vascular bed.

Table 2 presents the percentage of vascular pulp area in relation to the total pulp area recorded in the groups. Group I (no betamethasone after cavity preparation) presented
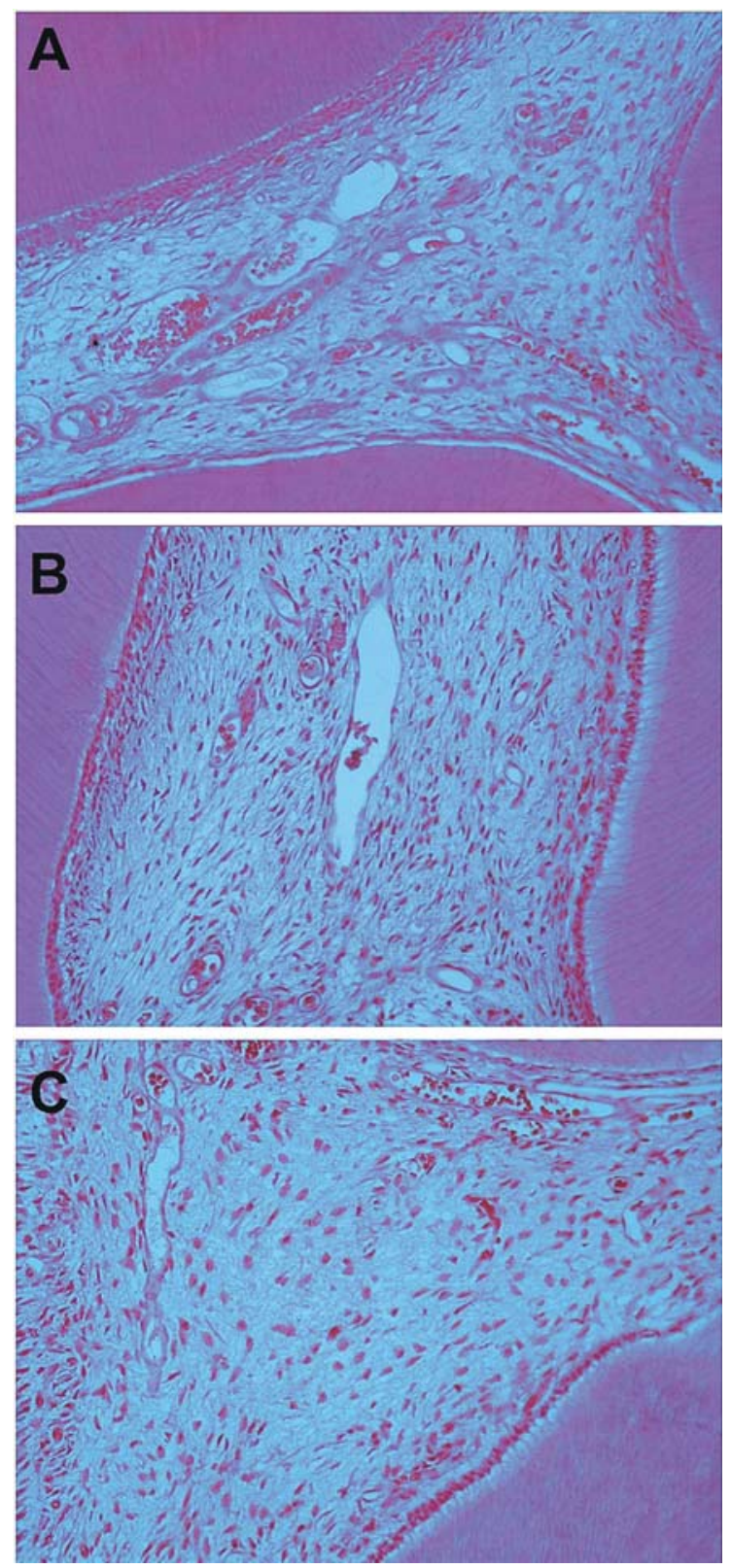

FIGURE 1- Histological images of the pulp tissue in Groups I, II and III. (A) Histological section from a specimen that received no corticosteroid application on the dentin after cavity preparation (Group I) (Original magnification $\times 100$ ); (B) Histological section from a specimen that received topical application of betamethasone after cavity preparation (Group II) (Original magnification $\times 100)$; (C) Histological section of healthy pulp (Group III) (Original magnification $\times 100$ ) 
significantly higher values $(\mathrm{p}=0.01)$ than Group II (betamethasone after cavity preparation) and Group III (control), which means a significantly larger vascular area

Images from microscopic slides of specimens from Group II were closer in quality to those from Group III and presented a higher percentage of the area occupied by loose connective tissue. Figure 1 shows histological images of the pulp tissue in Groups I, II and III.

\section{DISCUSSION}

Knowledge of the principles of the antiinflammatory action of corticosteroids has shown that these agents are capable of controlling the development of inflammatory processes from the irritative phase by inhibiting the production of arachidonic acid and consequently the production of prostaglandins, which have an important role in inducing vasodilatation and increasing vascular permeability. Thus, the vascular inflammatory events tend to diminish. Such aspects were confirmed by the results of the present study, which showed a significantly decreased vasodilatation and a significantly smaller number of blood vessels in Group II (betamethasone applied after cavity preparation) when compared to Group I (cavity preparation only).

Unlike most studies, which focus on evaluating the inflammatory pulp response, the present study was designed to establish vascular measurements rather than observing cells. This methodological approach allows for testing the properties of the medication within a short experimental period while the vascular events involved in the inflammatory process are prominent and the cell events are not yet clearly visualized ${ }^{4}$.

Measuring the magnitude of dilatation (vascular area) and counting the number of blood vessels have been used in a previous study ${ }^{17}$ that compared the vascular status of deciduous and permanent teeth by means of computer-aided analysis. Those authors observed an increase in vascularization that was related to caries progression and was not followed by an increase in the number of blood vessels. In the present study, these measurements were also obtained digitally, which grants accuracy to the data.

The results of this study are consistent with those of previous investigations $\mathrm{s}^{6,11,12}$, which emphasize the viability of preventing pulp inflammation by using topical corticosteroids on dentin. The clinical benefits of this practice will find support in our findings, which confirmed a pulpal biology favorable to conservative therapy in cases of hyperemia. This is corroborated by the fact that Group II, in which betamethasone was applied after cavity preparation, did not differ significantly from Group III, which represented pulp health. It should be pointed out that the same results were valid for the total sum of the samples and for each animal individually. Therefore, the application of corticosteroid diminished the intensity of the vascular phase in the inflammatory process in all animals investigated.

It is known that the temperature of the pulp increases a little during cavity preparation. Pulp reaction can be diminished if proper operative technique and cooling conditions. However, due to the particular characteristics of the pulp-dentin complex, there will be an inflammatory response to the aggression, which is translated into an increase in activity of the nervous tissue, blood vessels and the immune system ${ }^{4}$. The fact that microbial agents and some restorative materials can cause inflammatory reactions may contribute to aggravate the scenario ${ }^{8,10}$. Therefore, as some kind of pulp response is expected, efforts should be directed at preventing the inflammatory conditions from worsening by taking advantage of the dentinal permeability and the intimate relation between pulp and dentin ${ }^{15}$. As far as pulp inflammation is concerned, Hume and Massey ${ }^{7}$ (1990) suggested that pulpal inflammation be treated primarily by removal of the irritant cause and that corticosteroids should be applied immediately over the dentin followed by a restoration with agents composed mainly of zinc oxide eugenol, based on the fact that the release of chemicals may diffuse through dentine and help the affected dental pulp. In a similar manner, Ciarlone and Pashley ${ }^{3}$ (1992) in a review of the literature, suggested that it is possible to use the dentinal permeability with therapeutic purposes. They also suggested using anesthetics to avoid pain from disseminating, using painkillers to control pain, and using antibiotics to treat infection.

In the present study, the fact that the animals were sacrificed $10 \mathrm{~min}$ after the experiment allowed verifying that betamethasone penetrates the dentinal tubules and reaches the pulp tissue rapidly, with an immediate antiinflammatory action. Thus, the ability of betamethasone to act preventing further development of an inflammatory process is validated by using dentinal permeability, and this fundamental to explain why this medication should be used clinically after deep cavity preparation and after preparation of vital teeth that are about to receive a prosthetic crown.

According to Srisawasdi and Pavasant ${ }^{18}$ (2007), corticosteroids promote fibronectin synthesis and suppress nerve growth factor secretion, suggesting that this reagent could be used clinically to reduce pain and promote dental pulp tissue healing. Why is betamethasone the medication of choice? Previous studies confirm its greater antiinflammatory potential in relation to other topical corticosteroids ${ }^{5}$. In the present study the inflammatory components of the inflammation were not investigated because that 10-min period between application of betamethasone and euthanasia of the animals is not long enough to allow for cell margination and exudation of the inflammatory cell components from the blood vessels. However, the medication acts on the vascular phase of the inflammation and can cause the inflammatory symptoms to subside for all of the following phases. The efficacy of betamethasone can be verified by its penetration into the dentinal tubules, having a favorable action on vascular response. 


\section{CONCLUSION}

Under the tested experimental conditions, betamethasone applied on the dentin proved to reduce the vascular phase of pulp inflammation regarding vessel diameter and number of blood vessels.

\section{REFERENCES}

1- Accorinte ML, Loguercio AD, Reis A, Costa CA. Response of human pulps capped with different self-etch adhesive systems. Clin Oral Investig 2008;12(2):119-27.

2- Büyükgüral B, Cehreli ZC. Effect of different adhesive protocols vs calcium hydroxide on primary tooth pulp with different remaining dentin thicknesses: 24-month results. Clin Oral Investig. 2008;12(1):91-6.

3- Ciarlone AE, Pashley DH. Medication of dental pulp: a review and proposals. Endod Dent Traumatol. 1992;8(1):1-5.

4- Cotran RS, Kumar V, Collins T. Robbins' pathologic bases of disease. Philadelphia: WB Saunders; 2004

5- Fachin EVF, Zaki AE. Histology and lysosomal cytochemistry of the postsurgically inflamed dental pulp after topical application of steroids. I. Histological study. J Endod. 1991;17(9):457-60.

6- Fry AE, Watkins RF, Phatak NM. Topical use of corticosteroids for the relief of pain sensitivity of dentine and pulp. Oral Surg Oral Med Oral Pathol. 1960;13(5):594-7.

7- Hume WL, Massey WL. Keeping the pulp alive: the pharmacology and toxicology of agents applied to dentine. Aust Dent. 1990;35(1):32-7.

8- Love RM, Jenkinson HF. Invasion of dentinal tubules by oral bacteria. Crit Rev Oral Biol Med. 2002;13(2):171-83.

9- Manchikanti L. Role of neuraxial steroids in interventional pain management. Pain Physician. 2002;5(2):182-99

10- Mjor IA, Ferrari M. Pulp-dentin biology in restorative dentistry. Part 6: Reactions to restorative materials, tooth-restoration interfaces and adhesive techniques. Quintessence Int. 2002;33(1):35-63.

11- Mjor JH, Levik T. Pulp healing subjacent to corticosteroid-covered and amalgam-covered dentin. Oral Surg Oral Med Oral Pathol. 1975;40(6):789-95

12- Mosteller JH. Use of prednisolona in the elimination of postoperative thermal sensitivity: a clinical study. J Prosthet Dent. 1962;12(6):1176-9.

13- Negm MM. Intracanal use of a corticosteroid-antibiotic compound for the management of prosttreatment endodontic pain. Oral Surg Oral Med Oral Pathol Oral Radiol Endod. 2001;92(4):35-9.

14- Nakanishi T, Shimizu H, Matsuo T. An immunological study on cycloxygenase-3 in human dental pulp. J Endod. 2001;27(6):385-8

15- Pashley DH. Dynamics of the pulpo-dentin complex. Crit Rev Oral Biol Med. 1996;7(2):104-33.

16- Rittner HL, Back A, Stein C. Pro-algesic versus analgesic actions of immune cells. Curr Opin Anaesthesiol. 2003;16(5):527-33.

17- Rodd HD, Boissonade FM. Vascular status in human primary and permanent teeth in healh and disease. Eur J Oral Sci. 2005;113(2):12834
18- Srisawasdi S, Pavasant P. Different roles of dexamethasone on transforming growth factor-beta1-induced fibronectin and nerve growth factor expression in dental pulp cells. J Endod. 2007;33(9):1057-60.

19- Trowbridge HO, Emiling RC. Inflammation: a review of the process. Chicago: Quintessence; 1997.

20- Vibalariu A, Cãruntu ID, Bolintineanu S. Morphological changes in dental pulp after the teeth preparation procedure. Rom J Morphol Embryol. $2005 ; 46(2): 131-6$ 